\title{
QUALIDADE DE SOLOS EM SUBSISTEMAS AGRÍCOLAS NO SERTÃO PARAIBANO POR MEIO DA CROMATOGRAFIA EM PAPEL
}

\section{Thiago do Nascimento Coaracy¹; David Marx Antunes de Melo²; Paulo César Carneiro Barreto $^{3}$; Raniery Santiago Cantalice ${ }^{4}$; Thiago Bernardino de Sousa Castro ${ }^{5}$; Moisés Paiva da Rocha Mendes';}

${ }^{1}$ Mestre em Ciências Agrárias (Agroecologia), UFPB, Bananeiras, Paraíba, ${ }^{2}$ Doutorando/Programa de Pós-Graduação em Agronomia, UFPB, Areia, Paraíba, ${ }^{3}$ Bacharelando em Agroecologia, UFPB, Bananeiras, Paraíba, ${ }^{4}$ Bacharelando em Agroecologia, UEPB, Lagoa Seca, Paraíba, ${ }^{5}$ Mestre em Eng. Agrícola, UFCG, Campina Grande, Paraíba, ${ }^{6}$ Engenheiro Agrônomo e Extensionista - EMPAER, Brejo do Cruz, Paraíba.

\section{DOI: $10.47094 / I C O N N E C A .2021 / 20$}

\section{RESUMO}

A avaliação da qualidade do solo tal como a Cromatografia de Pfeiffer vem sendo de grande utilidade para o manejo em agroecossistemas produtivos, principalmente pelo baixo custo e fácil entendimento. Assim, o objetivo foi avaliar o solo dos quatro subsistemas produtivos com a Cromatografia. Testamos a hipótese que a mata possui solos com melhor qualidade. $\mathrm{O}$ trabalho foi realizado no município de Brejo do Cruz-PB, no Sítio Flor do sertão em quatro subsistemas: roçado de milho, algodão agroecológico, quintal produtivo, e mata de caatinga. Foram coletadas amostras de solo compostas dos sistemas produtivos, de 0 à $15 \mathrm{~cm}$ e levadas para realização da prática da cromatografia. O subsistema Mata apresentou o melhor cromatograma, obtendo excelência em suas três zonas com notas máximas. Entre os subsistemas agrícolas, o subsistema Milho apresentou o melhor cromatograma obtendo maior nota de qualidade do solo, seguido pelo subsistema Algodão e por último o subsistema Quintal.

PALAVRAS-CHAVE: Neossolo. Agroecossistemas. Diferentes manejos.

ÁREA TEMÁTICA: Gestão Ambiental.

\section{INTRODUÇÃO}

O manejo racional dos solos deve ser considerado quando se inicia um planejamento produtivo e reflete no status ambiental ou a condição de sustentabilidade dos agroecossistemas. Logo, os indicadores de qualidade do solo podem ser classificados como físicos químicos e biológicos. (ARAÚJO \& MONTEIRO, 2017). Nesse sentido, um método para avaliação da qualidade do solo utiliza de uma metodologia que consiste na interpretação das características reveladas por imagem como cor, forma e harmonia, a Cromatografia em papel circular. (PERUMAL, et al. 2016). 
Essa pesquisa foi motivada pela necessidade de se comparar e demonstrar as diferenças nas qualidades do solo com manejos distintos. A unidade da pesquisa é um sítio experimental em agroecologia no semiárido e busca investigar e divulgar esse método de análise da saúde do solo, a Cromatografia, que no Brasil vem sendo uma técnica difundida. (PINHEIRO, 2015).

Devido à importância de se conhecer o solo que se trabalha, a fim de poder acompanhar o seu desenvolvimento ou degradação, é importante que se faça uma análise periódica desse solo. (PRIMAVESI, 2016). A análise através de cromatogramas permite uma independência dos agricultores para fazer um acompanhamento periódico, pois os materiais são de baixo custo. (PILON, 2018; PINHEIRO, 2015).

Assim, a Cromatografia do Solo consiste em um método refinado de análise integrada das dimensões do solo e de fácil assimilação para famílias agricultoras, permitindo que técnicos e agricultores percebam as carências e qualidades do solo. No solo existe vida, interação e integração, e dentro da perspectiva metodológica dessa técnica, podemos também avaliar a presença da matéria orgânica (PILON, 2018; PINHEIRO, 2015).

O estudo e utilização de métodos mais acessíveis inerentes a análise da qualidade do solo como a cromatografia, é essencial, pois se trata de um importante indicador do manejo de terras agrícolas e, consequentemente, da sustentabilidade dos agroecossistemas (PRIMAVESI, 2016; CARDOSO \& FÁVERO, 2018). O objetivo da proposta foi caracterizar a qualidade do solo por meio da cromatografia de Pfeiffer de quatro subsistemas sob diferentes usos e manejos no sertão paraibano. Neste trabalho testamos a hipótese de que a mata possui solos com melhor qualidade.

\section{METODOLOGIA}

A pesquisa foi realizada em subsistemas do sítio Flor do Sertão, localizado no município de Brejo do Cruz, sertão paraibano. Os solos dos subsistemas foram classificados conforme o Sistema Brasileiro de Classificação de Solos - SiBCS como NeossoloRegolítico (Embrapa, 2013) .

Inicialmente realizaram-se coletas de amostras compostas de solos na profundidade de 0-15 cm, em quatro subsistemas: Milho, Algodão Agroecológico, Quintal Produtivo e Mata de Caatinga. Para cada amostra foram realizadas duas repetições. No tocante aos cromatogramas do solo, a realização e interpretação foram consideradas pacto aos procedimentos e critérios usados por PILON (2018). 
Figura 1. Guia de interpretação das zonas no cromatograma: A: Zona Central (ZC), Estrutura do solo; B e C: Zona Interna (ZI), nutrientes; D: Zona Externa (ZE), Microbiologia do solo; E: Zona para anotações; F: ligação entre zonas; G: figura do cromatograma de um solo saudável; H: explosão em nuvem indica disponibilidade de nutrientes; I: são os radiais ligados à diversidade e complexidade enzimática e frações húmicas.

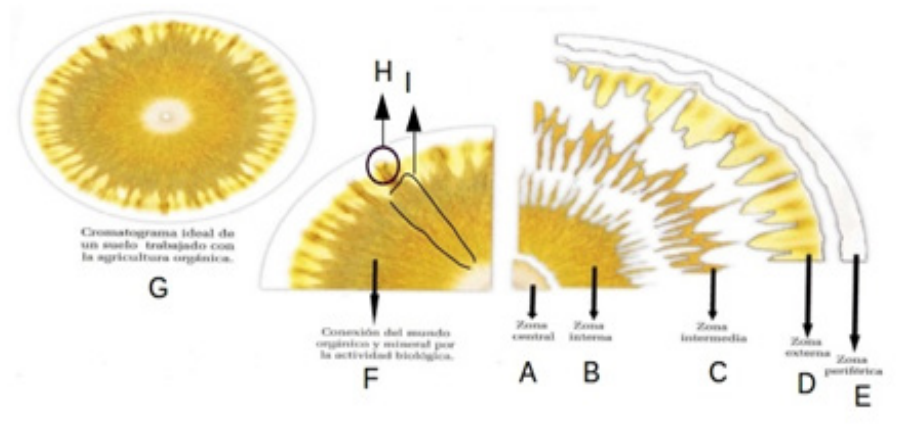

Para a interpretação dos cromatogramas foi utilizado um método que consiste basicamente das cores do semáforo, com categorias em que o número 1 e 2 correspondem ao vermelho, presença de uma zona (deficiente), já o número 3 a cor amarelo com categoria (suficiente), o numero 4 a cor azul com boas zonas no croma (bom) e 5 a cor verde que remete a (excelente) (MELO, et al., 2019).

\section{RESULTADOS E DISCUSSÕES}

Como resultados, as análises dos cromatogramas dos diferentes subsistemas avaliados permitiram a constatação de que houve variações entre os subsistemas avaliados (Figura 2).

No que diz respeito aos subsistemas agrícolas, o Milho foi quem logrou a melhor cromatograma obtendo boa nota para as três zonas do cromatograma, possui boa estrutura com cor azul para os três semáforos, logo, seu cromatograma apresenta boa harmonia, integração entre suas zonas por meio das flechas e boa formação da ZE pelo tamanho e formato dos dentes (MELO et al., 2019).

O subsistema Milho é a área que mais tempo passou em pousio e trabalha com implementos manuais. Sobre o subsistema Algodão orgânico para todas suas zonas apresentou mediana integração no formato do cromatograma, obtendo condição média, com semáforos na coloração amarela. Provavelmente isso se deve às práticas de manejo adotadas, visto que foi utilizado trator para arar a terra o que contribui para a desestruturação e compactação do solo, como pode ser percebido na ZC (PIAN, 2017) (Figura 2).

Em relação ao subsistema Quintal, o mesmo apresentou a ZC muito pequena, uma condição ruim que aponta o solo compactado. Possivelmente isto se deve ao fato da área receber maior tráfego de pessoas por encontrar-se em torno da residência. Sobre a ZI e ZE, o subsistema logrou coloração amarela, que indica média qualidade do solo. Na ZI pode ser percebida a redução das flechas radiais e uma mancha acinzentada, possivelmente seja precipitação do sódio (PINHEIRO, 2015; PERUMAL et al., 2016) . 
Por fim, a Mata foi o subsistema avaliado que apresentou o melhor cromatograma obtendo melhores notas inerentes à qualidade do solo. Nota-se que o cromatograma do solo da mata possui zonas maiores e excelente formato e harmonia, por ser um ambiente ecológico que possui seu solo conservado (PILON et al 2018) (Figura 2).

Figura 2. cromatogramas dos subsistemas avaliados.

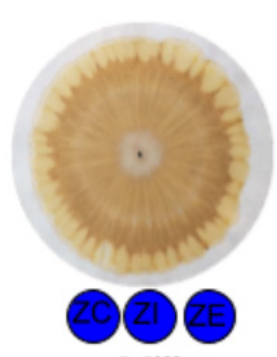

Milho

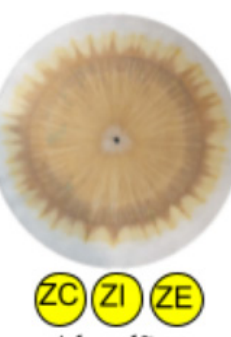

Algodão

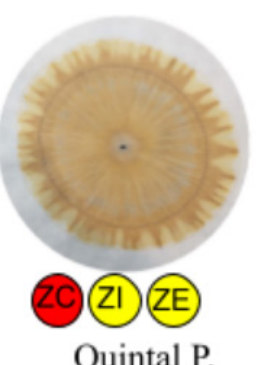

Quintal P.

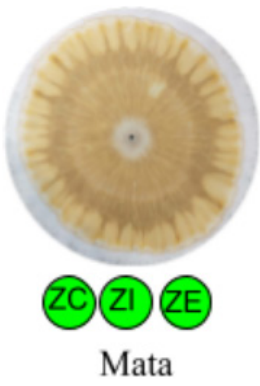

Mata

\section{CONSIDERAÇÕES FINAIS}

O subsistema da Mata apresentou o melhor cromatograma, obtendo excelência em suas três zonas com notas máximas.

Entre os subsistemas agrícolas, o subsistema Milho apresentou o melhor cromatograma obteve maior nota de qualidade do solo, seguido pelo subsistema Algodão e por último o subsistema Quintal. Essas singularidades ocorreram em razão dos diversos tipos de uso e manejo adotados em cada subsistema avaliado. No geral, os cromatogramas indicaram que todos os solos possuem de médio à alta qualidade dos seus solos de acordo com as zonas dos cromatogramas, principalmente em relação à Zona Externa.

\section{PRINCIPAIS REFERÊNCIAS}

ARAÚJO, A. S. F; MONTEIRO, R. T. R. Indicadores biológicos da qualidade do solo. BiosciencJournal. Uberlândia, p. 66-75. 2007.

CARDOSO, I. M.; FÁVERO, C. Solos e agroecologia. (Coleção transição agroecológica). V. 4. Editores técnicos - Brasília, DF: Embrapa, 373 p. 2018.

MELO D. M. A.; REIS, E. F.; COARACY, T. N.; SILVA, W. A. O.; ARAÚJO, A. E. Cromatografiade Pfeiffer como indicadora agroecológica da qualidade do solo em agroecossistemas. Revista Craibeiras de Agroecologia - ISSN 2594-9152 v. 4, n. 1, UFAL - Alagoas - AL. 2019.

PERUMAL, K.; ANANTHI, S.; ARUNKUMAR, J. Innovative and simplest alternative analytical technology (AAT) for testing soil nutrients, Journal of Soil Science Research (1). 2016. 
PIAN, L. B. Chromatography of Pfeiffer: Principles, method and use in perception of soils, 2017. PILON, L. C.; CARDOSO, J. H.; MEDEIROS, F. S. Guia Prático de Cromatografia de Pfeiffer. Embrapa Clima Temperado. DOCUMENTOS 455. Pelotas, RS. 2018.

PINHEIRO, S.. Saúde do Solo: Biopoder camponês versus agronegócio. Rio Grande do Sul: Salles Editora, 224 p. 2015.

PRIMAVESI, A. M. Manual do solo vivo. São Paulo: Expressão Popular, 2016. 